\title{
Augmented Inertial Response of Multi-level Converters using Internal Energy Storage
}

\author{
C.E. Spallarossa, M.M.C. Merlin, T.C. Green \\ Control and Power Research Group \\ Imperial College London, London, UK \\ claudia.spallarossa10@imperial.ac.uk
}

\begin{abstract}
During the recent years, the number of High Voltage Direct Current (HVDC) links, used for accommodating renewable energy sources and for interconnecting different power systems, has increased significantly. Apart from enhancing system stability, HVDC links can be used to provide ancillary services, such as frequency support. This paper investigates the potential of the energy storage capability of Modular Multi-level Converters (MMCs) to contribute to the frequency response. MMCs provide fast released energy through their cells capacitor that may be used to improve the system inertial response during the fault transient after a loss of generation event. To assess the effect of the converter energy storage capability, a mixed $\mathrm{AC}$ and DC transmission platform is developed in PowerFactory. It consists of a multi-machine system including a point-to-point MMC based HVDC link. A generation outage is applied to investigate the contribution of the MMC energy storage capability to the frequency recovery.
\end{abstract}

Index Terms-HVDC, MMC, converter energy storage, multimachine system, inertial response.

\section{INTRODUCTION}

Traditional AC systems are characterized by a dominant presence of synchronous generation and rely on inertial, primary, secondary and tertiary response to ensure the balance between supply and demand [1]. Recently, the large penetration of renewable energy sources in AC systems has led to the displacement of conventional generators, which has caused a reduction in the ability of contributing to inertial response and of participating to primary control [2]. Furthermore, to accommodate the increase in electricity generation and to deal with the significant penetration of renewable energy, the number of HVDC transmission links is expected to increase significantly [3]. These will serve as mean of connection to offshore wind energy as well as corridors between power systems of different countries in the perspective of the European Super Grid [3]. Hence, the HVDC option could be properly exploited as an alternative solution to address the stability issues and to enhance system reliability. For example, voltage source converters (VSC) offer a broad variety of ancillary services, including frequency support [4], [5].

MMCs are able to store energy in the stacks thanks to the presence of cell capacitors. This is a fast released energy that may be applied to improve the system inertial response after a frequency event. The energy contained in the stacks may be extracted and injected into the $\mathrm{AC}$ grid to reduce the gradient of the inertial response during the initial post-fault transient. However, the energy content of the stacks is small and it varies according to the rating of the converter [6].

This paper aims to assess whether the energy stored in the MMC stacks could contribute to the frequency recovery. To facilitate this, an MMC based HVDC link has been introduced in a multi-machine system and the frequency response profile is observed after a generation outage considering several control options.

\section{MIXED AC AND DC SYSTEM}

This section describes the mixed AC and DC test system used. A reduced dynamic model of a modular multi-level VSC is developed in PowerFactory and embedded in a multimachine AC grid.

\section{A. MMC Reduced Dynamic Model in PowerFactory}

The modular multi-level converter used in this study is the reduced dynamic model (RDM) developed in PowerFactory and presented in [7]. In an RDM the switching components are modelled as controlled voltage and current sources [8], [9]. The structure of an MMC RDM developed in PowerFactory is shown in Figure 1. Despite the differences with respect to the traditional converter layout, in [7] this topology is demonstrated to be equivalent to [8].

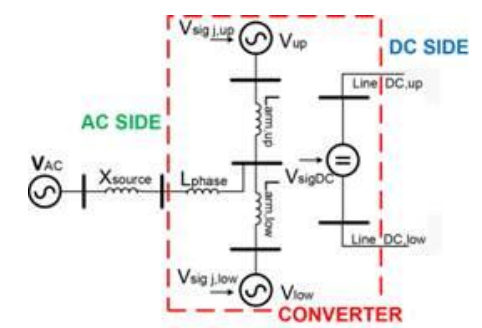

Figure 1: MMC RDM structure in PowerFactory.

The traditional control strategy for detailed MMC models [10], whose aim is the formulation of voltage reference signals for the switching cells, can be implemented on RDMs with some simplifications, such as the removal of the low level controller for the cell rotation algorithm. The control architecture is designed according to [7], [11]. As depicted in Figure 2, the control scheme consists of several nested control loops: the measurement phase, which evaluates the phase voltage and current in each stack; the energy controller, that addresses the regulation of the converter energy content; the 
current controller, which elaborates the control voltage signals to send to the stacks using reference and actual sets of currents, and the DC controller, in charge of regulating the DC side. The control architecture adopts an energy balancing approach. It considers the amount of energy stored in each stack to originate the reference signals that keep the converter energy content at nominal value and reduce to zero the energy exchange among the stacks [11].

\section{B. Multi-machine AC System}

The multi-machine system is a four-generator two-area system and it was proposed for the first time in [1]. The system consists of two symmetrical areas originally connected through AC corridors. In this case, generators are modelled as thermal units (steam power plants), with an inertia constant of $\mathrm{H}=6.25$ seconds each [1].

The system has been modified for supporting the implementation of an HVDC inter-tie, as shown in Figure 3. The HVDC system is equipped with modular multi-level VSC stations and it is arranged as a balanced monopole. The link transfers $800 \mathrm{MW}$ from Area 1 to Area 2, the rectifier end $\left(\mathrm{CONV}_{1}\right)$ is regulated in $\mathrm{P}-\mathrm{Q}$, while the inverter terminal
$\left(\mathrm{CONV}_{2}\right)$ is controlled in $\mathrm{V}_{\mathrm{dc}}-\mathrm{Q}$. The properties of the multimachine system, converters and DC cables are listed in Tables I, II and III respectively.

TABLE I: General Properties of Multi-Machine SyStem

\begin{tabular}{|c|c|c|}
\hline & P [MW] & Q [MVAr] \\
\hline G1 & 900 & 185 \\
\hline G2 & 900 & 235 \\
\hline G3 & 650 & 185 \\
\hline G4 & 650 & 202 \\
\hline Ld1 & 1020 & 100 \\
\hline Ld2 & 2020 & 250 \\
\hline
\end{tabular}

TABLE II: CONVERTERS PROPERTIES

\begin{tabular}{|c|c|c|c|c|}
\hline & \multicolumn{3}{|c|}{ CONV 1 } & \multicolumn{2}{|c|}{ CONV 2 } \\
\hline $\mathrm{V}_{\mathrm{ac}}$ & \multicolumn{2}{|c|}{$320 \mathrm{kV}$} & \multicolumn{2}{|c|}{$320 \mathrm{kV}$} \\
\hline $\mathrm{V}_{\mathrm{dc}}$ & $\pm 320 \mathrm{kV}$ & \multicolumn{2}{|c|}{ $\pm 320 \mathrm{kV}$} \\
\hline Set-point & $800 \mathrm{MW}$ & $0 \mathrm{MVAr}$ & $\pm 320 \mathrm{kV}$ & $0 \mathrm{MVAr}$ \\
\hline
\end{tabular}

TABLE III: DC CABLES PARAMETERS

\begin{tabular}{|c|c|c|c|}
\hline Parameter & Value & Parameter & Value \\
\hline $\mathrm{V}_{\text {rated }}[\mathrm{kV}]$ & $320 \mathrm{kV}$ & Resistance & $11.3 \mathrm{~m} \Omega / \mathrm{km}$ \\
\hline $\mathrm{I}_{\text {rated }}[\mathrm{kA}]$ & $1 \mathrm{kA}$ & Inductance & $0.362 \mathrm{mH} / \mathrm{km}$ \\
\hline length $[\mathrm{km}]$ & $100 \mathrm{~km}$ & Capacitance & $0.212 \mathrm{~F} / \mathrm{km}$ \\
\hline
\end{tabular}
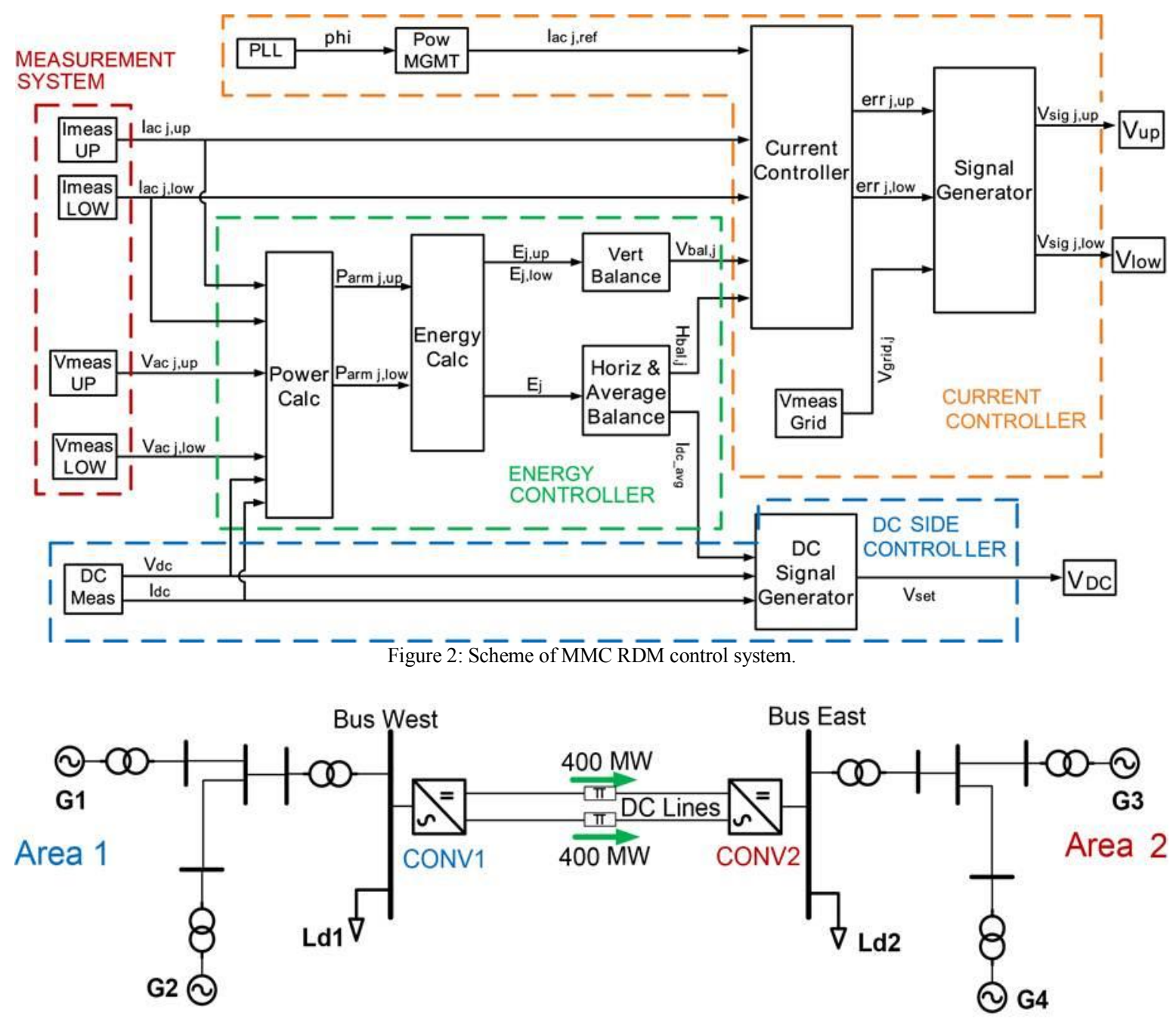

Figure 3: Multi-machine system with the addition of a HVDC link. 


\section{ENERGY STORAGE CAPABILITY OF MMC}

The capacitor of each cell of an MMC aims to keep the cell voltage close to its nominal value as current passes through the cell. This action allows the converter to store energy. The energy content of an MMC is small and varies according to the rating of the converter, on average it is $30-40 \mathrm{~kJ} / \mathrm{MVA}$ [12], [13].

In normal operation, the energy stored ensures the generation of the multi-step voltage waveform and the balance between the instantaneous $\mathrm{AC}$ and $\mathrm{DC}$ powers. In abnormal conditions, a portion of the converter stored energy could be released quickly and injected into the AC grid to improve the system inertial response in the initial post-fault transient (500 $\mathrm{ms}$ ). The effect that this energy may have on the inertial response of the multi-machine system after a generation outage has to be thoroughly investigated.

\section{A. Internal Energy Storage through the Energy Controller}

In the MMC RDM described in Section II.A, the energy controller is in charge of managing the average energy content of the converter stacks. The energy controller calculates the stack energy content considering the currents $\left(\mathrm{i}_{\mathrm{j}, \text { up }}\right.$ and $\left.\mathrm{i}_{\mathrm{j}, \text { low }}\right)$ and voltages $\left(\mathrm{v}_{\mathrm{j} \text {,up }}\right.$ and $\left.\mathrm{v}_{\mathrm{j}, \text { low }}\right)$ in each stack due to the absence of cells in the reduced version. Equations (1) and (2) define the total energy contained in every phase $(j=a, b, c)$ for the upper $E_{j, \text { up }}$ and lower $E_{j, \text { low }}$ stacks, where $E_{0}$ indicates the initial energy at $\mathrm{t}=0$.

$$
\begin{aligned}
E_{j, \text { up }}(t) & =\int_{0}^{t} v_{j, \text { up }}(t) i_{j, \text { up }}(t) d t+E_{0} \\
E_{j, \text { low }}(t) & =\int_{0}^{t} v_{j, \text { low }}(t) i_{j, \text { low }}(t) d t+E_{0}
\end{aligned}
$$

The total energy stored in the three phases of the converter $\mathrm{E}_{\mathrm{CONV}}$ is defined in (3), where $\mathrm{C}_{\text {cell }}$ is the cell capacitance, $\mathrm{V}_{\mathrm{DC}}$ is the converter nominal direct voltage, $n_{\text {stack }}$ is the number of stacks per converter and $\mathrm{N}_{\mathrm{sm}}$ is the number of sub-module per stack.

$$
E_{\text {CONV }}(t)=\sum_{j} E_{j, u p-l o w}(t)=\frac{n_{\text {stack }} N_{s m}}{2} * C_{c e l l} V_{D C}^{2}=3 \frac{C_{\text {cell }} V_{D C}^{2}}{N_{s m}}
$$

The number of sub-modules $\mathrm{N}_{\mathrm{sm}}$ is defined by (4), where $\mathrm{N}_{\text {redundancy }}$ indicates the number of redundant cells.

$$
N_{s m}=\frac{V_{D C}}{V_{\text {cell,nom }}}+N_{\text {redundancy }}
$$

The decoupling of the power references of the $\mathrm{AC}$ and $\mathrm{DC}$ sides $\left(\mathrm{P}_{\mathrm{ac}, \text { ref }}\right.$ and $\left.\mathrm{P}_{\mathrm{dc}, \text { ref }}\right)$ allows the converter energy content to deviate from the nominal value. As a consequence, the energy stored in the stacks can be rapidly released and used for the system inertial response after a frequency event.

In this case, the imbalance between the power references is produced by the introduction of a designed signal, named $\mathrm{En}_{\text {margin, }}$ in the energy controller and in the current controller of the MMC RDM control system. The addition of $\mathrm{En}_{\text {margin }}$ causes an alteration of $\mathrm{P}_{\mathrm{ac}, \mathrm{ref}}$, therefore the converter energy content is forced to deviate from the nominal level. Figure 4 shows that this is achieved by directly modifying the target of the energy controller and by a feed-forward term in which the derivative of the energy variation is used to change the power reference. This modifies the nominal set-point leading every arm to operate as an energy buffer between the AC and DC side. The action of the $\mathrm{En}_{\text {margin }}$ in the energy controller is described in Figure 5 .

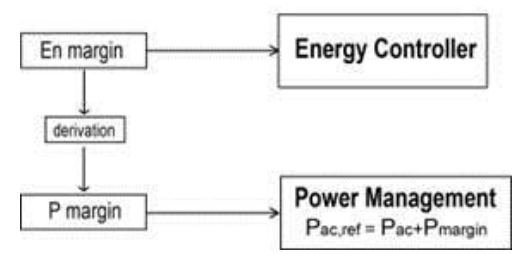

Figure 4: $\mathrm{En}_{\text {margin }}$ and $\mathrm{P}_{\text {margin }}$ in the MMC RDM control system.

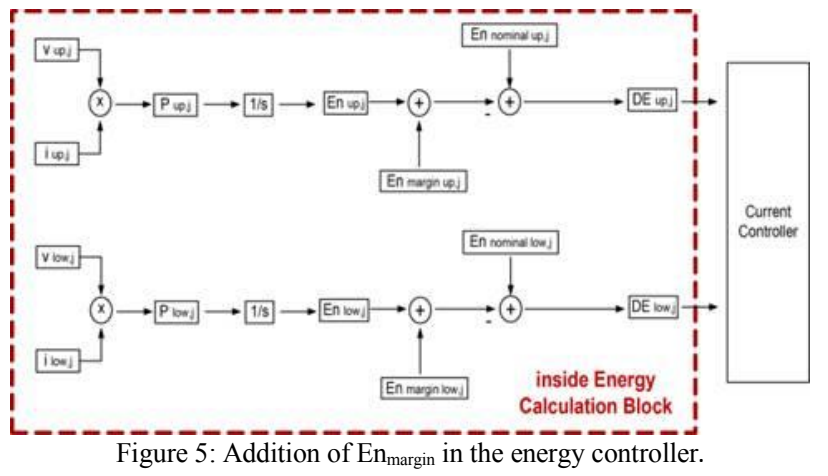

The signal $\mathrm{En}_{\text {margin }}$ is designed to extract up to $10 \%$ of the nominal energy content from the converter in a very short time frame $(400 \mathrm{~ms})$, and to inject it into the grid after a loss of generation event. Figures 6 (a) and 6 (b) illustrate the $E_{\text {margin }}$ used and Figures 6 (c) and 6 (d) show the power consequentially injected into the AC system. The energy starts to be extracted when the fault is applied and it stops when the system frequency eventually recovers to a new steady state. Afterwards, the energy is returned from the AC grid into the converter starting at $\mathrm{t}=80$ seconds.

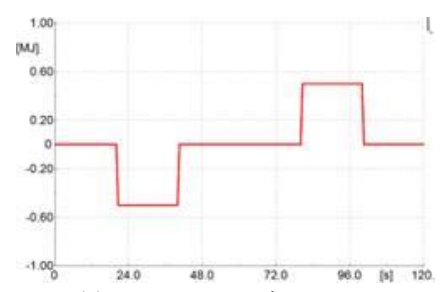

(a) Energy margin $\mathrm{En}_{\text {margin }}$

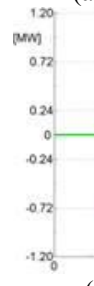

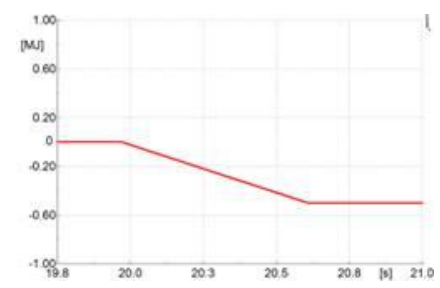

(b) Zoom of $\mathrm{En}_{\text {margin }}$

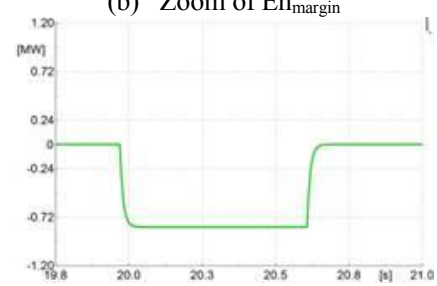

(d) Zoom of $\mathrm{P}_{\text {margin }}$
Figure 6: Energy margin signal and consequential Power margin signal. 


\section{SIMULATIONS AND RESULTS}

A set of time domain simulations using the mixed AC and DC system presented in Section II is performed in PowerFactory to investigate the effects of the energy storage on the system frequency recovery (inertial response). The initialization process lasts for a few seconds and it is not illustrated in the graphs, the time interval shown starts at 15 seconds once the system has reached the steady state. A loss of generation is applied at generator G2 in area 1. The dynamic response of the system is analyzed considering the different control options listed in Table IV. In Option 1 (red curve) the HVDC link acts as a firewall and no additional control is implemented. In Option 2 (green curve) the supplementary frequency droop control, which regulates the DC power transfer in the HVDC link after detecting a frequency deviation [14], is applied at $\mathrm{CONV}_{1}$ on the side of area 1. In Option 3 (blue curve) the converter energy storage is implemented at $\mathrm{CONV}_{1}$.

TABLE IV CONTROL OPTIONS

\begin{tabular}{|c|c|}
\hline Options & Control Conditions \\
\hline Option 1 & HVDC as firewall \\
\hline Option 2 & Supplementary frequency droop control at $\mathrm{CONV}_{1}$ \\
\hline Option 3 & Stack energy storage capability applied to $\mathrm{CONV}_{1}$ \\
\hline
\end{tabular}

\section{A. Internal Energy Storage of $M M C$}

A converter rated at $800 \mathrm{MW}$ is able to store a total amount of energy between 24-32 MJ. However, only a fraction of the total energy (up to $10 \%$ ) can be extracted from the converter without jeopardizing its operations. Following a loss of generation event, up to $3.2 \mathrm{MJ}$ can be extracted from the converter and injected into the AC grid during the initial post fault-transient for improving the inertial response.

The converter actual energy content $\mathrm{E}_{\text {conv }}$ is calculated using (3). Knowing that $\mathrm{V}_{\text {cell }}=1.5 \mathrm{kV}, \mathrm{V}_{\mathrm{DC}}= \pm 320 \mathrm{kV}, \mathrm{n}_{\text {stack }}=$ $6, \mathrm{~N}_{\text {redundancy }}=20$ and $\mathrm{C}_{\text {cell }}=9.28 \mathrm{mF}$, after calculations, $\mathrm{E}_{\text {conv }}=$ $28.2 \mathrm{MJ}$. This means that the converter stores $35 \mathrm{~kJ} / \mathrm{MVA}$. Considering the $10 \%$ limitation, only $2.8 \mathrm{MJ}$ can be extracted from the MMC. Such energy is then injected into the AC grid after the generation outage during the initial post-fault transient.

The inertia constant of an HVDC converter $\mathrm{H}_{\mathrm{CONV}}$ is calculated as the amount of time for which the device can output maximum power without receiving any input power. If the converter stores $35 \mathrm{~kJ} / \mathrm{MVA}$ and no recharging is contemplated, the device runs out of energy within 0.035 seconds when exporting a power of 1 p.u., therefore $\mathrm{H}_{\mathrm{CONV}}=$ 0.035 seconds. In a mixed AC and DC system characterized by a large share of conventional generation, the contribution of HVDC converters stored energy to the system inertial response is therefore significantly smaller than the contribution from synchronous generation units.

As mentioned in Section II.B, the inertia constants of the synchronous machines are $\mathrm{H}_{\mathrm{G} 1}=\mathrm{H}_{\mathrm{G} 2}=6.5$ seconds, then the inertia constant of the area is $\mathrm{H}_{\text {Areal }}=6.5$ seconds. The inertia constant of the converter is $\mathrm{H}_{\mathrm{CONV} 1}=0.035$ seconds. The contribution of the converter to the system inertial response is therefore found to be far smaller than the contribution from the synchronous generators (less than $0.5 \%$ ). These results are confirmed through the analysis of the system dynamic response following a generation outage.

\section{B. Dynamic System Response}

The system dynamic response is illustrated in Figures 7-12. The loss of generation of $70 \mathrm{MW}$ applied at unit G2 at $\mathrm{t}=20$ seconds is shown in Figure 7 for all the control options considered. In a system of such size, this fault causes a severe effect on the frequency profile.

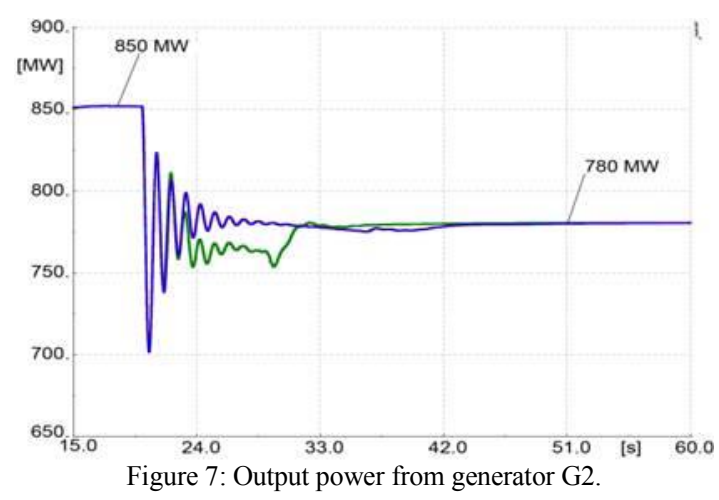

Figures 8 and 9 illustrate the frequency response of area 1 and area 2. In Option 1, the HVDC link is operated as a firewall and the two areas are decoupled. In area 1 the frequency nadir reached is $49.4 \mathrm{~Hz}$, whilst the frequency in area 2 is kept at nominal value. The application of the supplementary frequency droop control in Option 2 improves the frequency nadir to $49.59 \mathrm{~Hz}$ in area 1 , at cost of reducing the DC power transfer. The two areas become coupled and the frequency in area 2 is observed to vary (Figure 9). The postfault equilibrium is achieved 14 seconds faster than in the previous case. In Option 3, a portion of the energy content of $\mathrm{CONV}_{1}$ is injected into area 1 and it acts on the inertial response of this area during the initial post-fault transient (400 $\mathrm{ms})$. The frequency profile from Option 3 is nearly identical to the one from Option 1 (Figure 8) because the converter energy content is not large enough to have any significant effects on the system inertial response. A closer frame of the frequency profile is shown in Figure 10, where the inertial response is observed to be identical for the three cases.

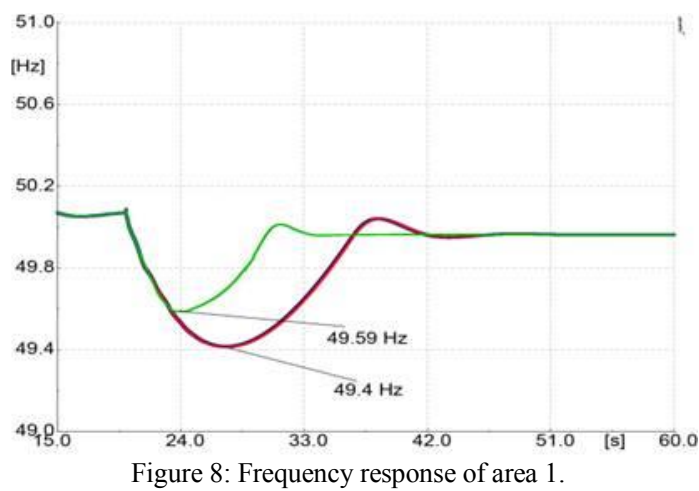



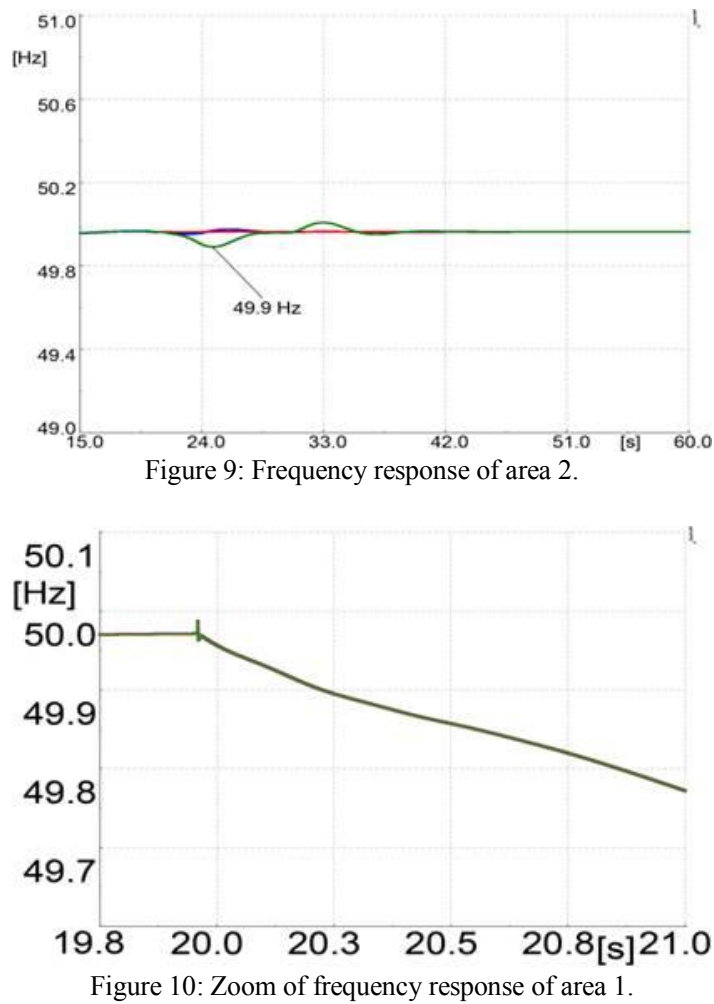

The DC power transfer between area 1 and area 2 is shown in Figure 11. The DC power flow varies only with the implementation of the supplementary frequency control (Option 2). The supplementary scheme is active for 10 seconds until the frequency in area 1 recovered within the statutory limits ( $\pm 5 \%$ of nominal frequency) [15].

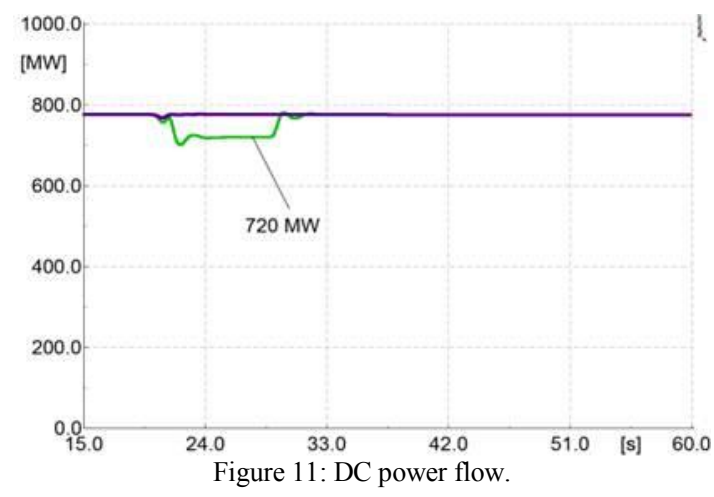

The energy content of $\mathrm{CONV}_{1}$ is illustrated in Figure 12. The total energy is kept at nominal value $(28 \mathrm{MJ})$ throughout the disturbance for Options 1 and 2. In Option 3, the application of the $\mathrm{En}_{\text {margin }}$ signal allows the extraction of $10 \%$ of the nominal energy $(2.8 \mathrm{MJ})$ and the injection into area 1. The energy starts to be extracted from the converter at $t=20$ seconds (simultaneously to the beginning of the fault) until $t=$ 40 seconds (when the frequency gains a new post-fault steady state). The energy is returned to the AC system later, long after the fault is extinguished.

An initial large transient is observed in the stored energy at $\mathrm{t}=20$ seconds when the energy starts to be extracted. This is due to the design of the $\mathrm{En}_{\text {margin }}$ signal. As shown in Figure 6(b), the gradient of such signal causes a large transient in the energy stored in the converter. A further control loop may be applied to the MMC RDM to contain this transient.

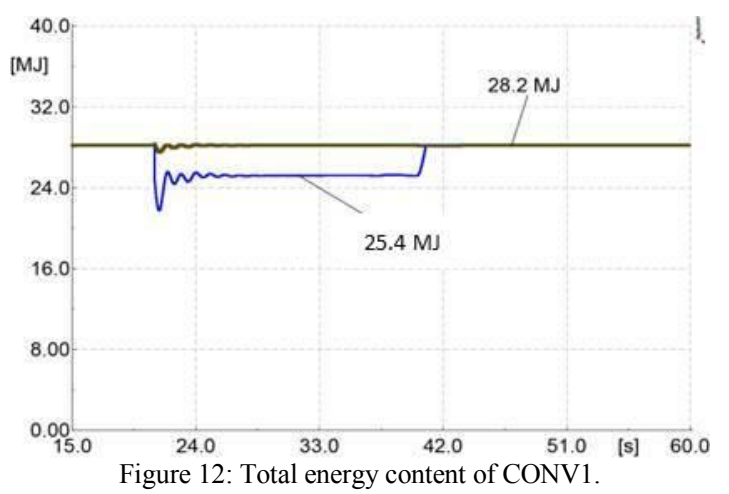

\section{CONCLUSIONS}

Due to the large penetration of renewable energy sources along with the necessity of interconnecting different power system for bulk power transfers, the number of HVDC links has increased significantly. The presence of HVDC corridors in power grids brings several advantages to system stability and offers ancillary services for frequency recovery, such as the energy storage capability of MMCs. However, in a conventional transmission system characterized by a dominant presence of synchronous generation this ability has been observed to have a small effect on the inertial response after a generation outage.

The injection of a portion of the energy stored in the converter into AC grids affected by loss of in-feed events may have a more significant effect on the frequency response in a different system configuration, such as a reduced-inertia system where the thermal generators will be replaced by wind farms. Furthermore, this concept could be applied in combination with the supplementary frequency control in order to improve the frequency recovery both in terms of inertial and and primary response

\section{ACKNOWLEDGMENT}

The authors gratefully acknowledge the financial support provided by the Top \& Tail Transformation program (ESPRC grant EP/I031707/1) for Ms Spallarossa, and the UK Power Electronics Centre (ESPRC grant EP/K035096/1) for Dr Merlin.

\section{REFERENCES}

[1] P. Kundur, Power System Stability and Control, 6 ed., McGrawHill, 1994.

[2] North America Electric Reliability Corporation (NERC), "Interconnection requirements for variable generation. Technical report." NERC, Altlanta, GA 2012.

[3] D. Van Hertem, M. Ghandhari and M. Delimar, "Technical limitations towards a SuperGrid - A European prospective," in 
Energy Conference and Exhibition (EnergyCon), 2010 IEEE International, 2010, pp. 302-309.

[4] A. Junyent Ferre, Y. Pipelzadeh and T. Green, "Blending HVDClink energy storage and offshore wind turbine inertia for fast

frequency response," Sustainable Energy, IEEE Transactions on, vol. PP, no. 99, pp. 1-8 2015

[5] B. Silva, C.L. Moreira, L. Seca, Y. Phulpin and J.A. Peas Lopes, "Provision of inertial and primary frequency control services using offshore multiterminal HVDC networks," Sustainable Energy, IEEE Transactions on, vol. 3, no. 4, pp. 800-808 2012.

[6] C. Oates, "Modular multilevel converter design for VSC HVDC applications," Emerging and Selected Topics in Power Electronics, IEEE Journal of, vol. PP, no. 99, pp. 1-1 2014

[7] C.E. Spallarossa, M.M.C. Merlin, Y. Pipelzadeh and T.C. Green, "Reduced Dynamic Model of a Modular Multi-level Converter in PowerFactory," in IEEE Compel 2015, Vancouver BC, Canada, 2015.

[8] H. Saad, J. Peralta, S. Dennetiere, J. Mahseredjian, J. Jatskevich, J.A. Martinez, A. Davoudi, M. Saeedifard, V. Sood, X. Wang, J. Cano and A. Mehrizi-Sani, "Dynamic averaged and simplified models for MMC-based HVDC transmission systems," Power Delivery, IEEE Transactions on, vol. 28, no. 3, pp. 1723-1730 2013.

[9] H. Saad, S. Dennetière, J. Mahseredjian, P. Delarue, X. Guillaud, J. Peralta and S. Nguefeu, "Modular multilevel converter models for electromagnetic transients," Power Delivery, IEEE Transactions on, vol. 29, no. 3, pp. 1481-1489 2014.
[10] Zhao Yan, Hu Xue-hao, Tang Guang-fu and He Zhi-yuan, "A study on MMC model and its current control strategies," in Power Electronics for Distributed Generation Systems (PEDG), 2010 2nd IEEE International Symposium on, 2010, pp. 259-264.

[11] M.M.C. Merlin, T.C. Green, P.D. Mitcheson, D.R. Trainer, R. Critchley, W. Crookes and F. Hassan, "The alternate arm converter: A new hybrid multilevel converter with DC-fault blocking capability," Power Delivery, IEEE Transactions on, vol. 29, no. 1, pp. 310-317 2014 .

[12] B. Jacobson, P. Karlsson, G. Asplund, L. Harnefors and T. Jonsson, "VSC-HVDC Transmission with Cascaded Two-Level Converters," in Cigre' 2010, B4-110, Paris, France, 2010.

[13] M.M.C. Merlin, T.C. Green, P.D. Mitcheson, F.J. Moreno, K.J. Dyke and D.R. Trainer, "Cell capacitor sizing in modular multilevel converters and hybrid topologies," in Power Electronics and Applications (EPE'14-ECCE Europe), 2014 16th European Conference on, 2014, pp. 1-10.

[14] C.E. Spallarossa, Y. Pipelzadeh and T.C. Green, "Influence of frequency-droop supplementary control on disturbance propagation through VSC HVDC links," in Power and Energy Society General Meeting (PES), 2013 IEEE, 2013, pp. 1-5.

[15] National Grid Electricity Transmission plc, "National Electricity Transmission System Security and Quality of Supply standard," National Grid, UK, Rep. 2.32012. 